\title{
Spontaneous Regression of a Large Hepatocellular Carcinoma with Multiple Lung Metastases
}

Tamiko Saito, Masafumi Naito, Yuki Matsumura, Hisaaki Kita, Tomoyo Kanno, Yuki Nakada, Mina Hamano, Miho Chiba, Kosaku Maeda, Tomoki Michida, and Toshifumi Ito

Department of Internal Medicine, Osaka Koseinenkin Hospital, Osaka, Japan

A 75-year-old Japanese man with chronic hepatitis C was found to have a large liver tumor and multiple nodules in the bilateral lungs. We diagnosed the tumor as hepatocellular carcinoma (HCC) with multiple lung metastases based on imaging studies and high titers of HCC tumor markers. Remarkably, without any anticancer treatment or medication, including herbal preparations, the liver tumor decreased in size, and the tumor makers diminished. Moreover, after 1 year, the multiple nodules in the bilateral lungs had disappeared. Fifteen months after the first medical examination, transcatheter arterial chemoembolization (TACE) was performed for the residual HCC. Because local relapse was observed on follow-up computed tomography, a second TACE was performed 13 months after the first one. At 4 years after the second TACE ( 7 years after the initial medical examination), there was no recurrence of primary or metastatic lesions. Spontaneous regression of HCC is very rare, and its mechanism remains unclear. Understanding the underlying mechanism of this rare phenomenon may offer some hope of finding new therapies, even in advanced metastatic cases. (Gut Liver 2014;8:569-574)

Key Words: Carcinoma, hepatocellular; Lung metastasis; Neoplasm regression, spontaneous

\section{INTRODUCTION}

Hepatocellular carcinoma (HCC) is a common malignancy and one of the major causes of death in the world, especially in Asia. ${ }^{1}$ The prognosis of advanced HCC remains poor, and the lung is the most frequent site of distant metastasis. Some reports have described cases of spontaneous regression of HCC and spontaneous regression of distant metastatic lesions from HCC, although the mechanisms leading to it remain unknown. Here we report a case of a 75-year-old man who showed spontaneous regression of a large HCC with multiple lung metastases.

\section{CASE REPORT}

A 75-year-old man with chronic hepatitis $\mathrm{C}$ and diabetes mellitus first visited our hospital for examination of a liver mass detected by abdominal ultrasonography. He described a 1-month history of abdominal pain. Gastric ulcer was detected by endoscopy and administration of the proton pump inhibitor was started. He had no history of alcohol abuse, smoking, blood transfusion, or steroid intake. He took ursodeoxycholic acid for a liver function disorder pointed out 20 years ago. He was diagnosed with diabetes when he was 45 years old, and under NPH insulin (12 U/day) injection from 65 years old. Physical examination revealed hepatomegaly without ascites. Laboratory studies showed elevated levels of liver enzymes and total bilirubin (Table 1). The results were negative for hepatitis B surface antigen but positive for antibody to hepatitis $\mathrm{C}$ virus. Tumor markers associated with HCC were markedly elevated, $\alpha$-fetoprotein (AFP) at $452,100 \mathrm{ng} / \mathrm{mL}$ and protein induced by vitamin $\mathrm{K}$ absence/antagonist-II (PIVKA-II) at 596,000 mAU/mL.

Contrast-enhanced computed tomography (CT) showed a huge heterogeneous dense mass (>20 cm in diameter) with enhancement involving the right hepatic lobe (Fig. 1). CT of the chest revealed multiple nodules in the bilateral lungs of up to $15 \mathrm{~mm}$ in diameter (Fig. 2A).

Based on typical imaging features and elevated specific tumor markers, the liver tumor was diagnosed as HCC, and the lung nodules were diagnosed as multiple lung metastases of HCC, although the diagnosis was not confirmed pathologically. Because of the advanced stage of HCC and estimated poor prognosis,

Correspondence to: Tamiko Saito

Department of Internal Medicine, Osaka Koseinenkin Hospital, 4-2-78, Fukushima, Fukushima-ku, Osaka 553-0003, Japan

Tel: +81-6-6441-5451, Fax: +81-6-6445-8900, E-mail: tami.matsuura@okn.gr.jp

Received on September 24, 2013. Revised on October 2, 2013. Accepted on October 2, 2013.

pISSN 1976-2283 eISSN 2005-1212 http://dx.doi.org/10.5009/gnl13358

(c) This is an Open Access article distributed under the terms of the Creative Commons Attribution Non-Commercial License (http://creativecommons.org/licenses/by-nc/3.0) which permits unrestricted non-commercial use, distribution, and reproduction in any medium, provided the original work is properly cited. 
Table 1. Laboratory Data from the First Medical Examination

\begin{tabular}{|c|c|}
\hline Variable & Value \\
\hline \multicolumn{2}{|l|}{$\mathrm{CBC}$} \\
\hline $\mathrm{WBC}, / \mu \mathrm{L}$ & 8,000 \\
\hline $\mathrm{RBC}, / \mu \mathrm{L}$ & $593 \times 10^{4}$ \\
\hline $\mathrm{Hb}, \mathrm{g} / \mathrm{dL}$ & 16.3 \\
\hline Ht, \% & 52.2 \\
\hline $\mathrm{PLT}, / \mu \mathrm{L}$ & $16.5 \times 10^{4}$ \\
\hline \multicolumn{2}{|l|}{ Coagulation } \\
\hline PT, \% & 62 \\
\hline \multicolumn{2}{|l|}{ Tumor maker } \\
\hline AFP, ng/mL & 452,100 \\
\hline PIVKA-II, mAU/mL & 596,000 \\
\hline \multicolumn{2}{|l|}{ Viral marker } \\
\hline HBs antigen & Negative \\
\hline HCV antibody & Positive \\
\hline \multicolumn{2}{|l|}{ Biochemistry } \\
\hline T-Bil., mg/dL & 1.7 \\
\hline AST, IU/L & 82 \\
\hline ALT, IU/L & 68 \\
\hline ALP, IU/L & 874 \\
\hline LDH, IU/L & 694 \\
\hline$\gamma$-GTP, IU/L & 340 \\
\hline $\mathrm{ChE}, \mathrm{IU} / \mathrm{L}$ & 64 \\
\hline T-Cho, mg/dL & 197 \\
\hline $\mathrm{TP}, \mathrm{g} / \mathrm{dL}$ & 7.0 \\
\hline $\mathrm{ALB}, \mathrm{g} / \mathrm{dL}$ & 3.5 \\
\hline BUN, mg/dL & 17 \\
\hline Cre, mg/dL & 0.70 \\
\hline CRP, mg/dL & 3.9 \\
\hline Glucose, mg/dL & 68 \\
\hline HbA1c, \% & 5.6 \\
\hline
\end{tabular}

CBC, complete blood counts; WBC, white blood cell; RBC, red blood cell; Hb, hemoglobin; Ht, hematocrit; PLT, platelet; PT, prothrombin time; AFP, $\alpha$-fetoprotein; PIVKA-II, protein induced by vitamin $\mathrm{K}$ absence/antagonist-II; HBs, hepatitis B surface; HCV, hepatitis C virus; T-Bil., total bilirubin; AST, aspartate aminotransferase; ALT, alanine aminotransferase; ALP, alkaline phosphatase; LDH, lactate dehydrogenase; $\gamma$-GTP, $\gamma$-glutamyl transpeptidase; ChE, cholinesterase; T-Cho, total cholesterol; TP, total protein; ALB, albumin; BUN, blood urea nitrogen; Cre, creatinine; CRP, C-reactive protein; HbA1c, hemoglobin A1c.

his family rejected further examination, including tumor biopsy and angiography, and any invasive therapy such as surgery.

At 3 months after the initial medical examination, the serum AFP had decreased markedly ( $944 \mathrm{ng} / \mathrm{mL}$ ). After 9 months, abdominal CT revealed that the liver mass had markedly decreased in size. Also, serum AFP and PIVKA-II had decreased to $107 \mathrm{ng} /$ $\mathrm{mL}$ and $34 \mathrm{mAU} / \mathrm{mL}$, respectively. The multiple nodules in the bilateral lungs had disappeared (Fig. 2B). After 13 months, HCC of $5 \mathrm{~cm}$ in size was detected in segment 5/6 of the liver (Fig. 3A, $\mathrm{B}$, and $\mathrm{C}$ ).

During this period, the patient had not received any anticancer treatment or medication including herbal preparations and denied any change in his daily habits. This phenomenon, therefore, was considered to be spontaneous regression of HCC with multiple lung metastases.

At 15 months after the first visit, because there was no further decrease in tumor size in the imaging studies and an increase in tumor markers (AFP, $407 \mathrm{ng} / \mathrm{mL}$; PIVKA-II, $59 \mathrm{mAU} / \mathrm{mL}$ ), the patient was subjected to transcatheter arterial chemoembolization (TACE) using gelatin-sponge and lipiodol combined with epirubicin and mitomycin C (Fig. 3D).

Two months after the first TACE, serum AFP and PIVKAII levels had decreased to the normal range. Because of local relapse, observed on follow-up CT (Fig. 4A), the second TACE was done at 13 months after the first TACE (Fig. 4B). The serum tumor markers did not increase at this time. At 4 years from the second TACE (7 years after the first medical examination), the patient continues to do well without any evidence of $\mathrm{HCC}$ recurrence (Fig. 5).

\section{DISCUSSION}

Spontaneous regression of cancer was defined by Everson and Cole $^{2}$ in 1966 as partial or complete disappearance of malignancy without specific treatment. The incidence of spontaneous regression was estimated to be one per 60,000 to 100,000 cases of malignancy. ${ }^{3}$ Spontaneous regression of cancer has been described for almost all kinds of tumors, with most reported cases being renal cell carcinoma, neuroblastoma, malignant melanoma, and malignant lymphoma. Spontaneous regression of HCC is a rare event, with an incidence rate of one in 140,000 cases of HCC. ${ }^{4}$ The mechanism of spontaneous regression of HCC is unknown. In previous reports, various factors have been proposed such as fever, infection, medical practice (blood transfusion, angiography, surgical trauma), medicine (herbal medicine, withdrawal from anabolic steroids, hormonal therapy, vitamin $\mathrm{K}$ ), change of blood flow (tumor thrombus, rapid tumor growth, gastrointestinal bleeding), abstinence from alcohol and stimulation of the immune system.

Ohtani et al..$^{5}$ analyzed 40 cases with spontaneous regression of HCC published in the literature in English from 1972 to 2001. In 23 of these, either radiological or histological complete regression was reported, whereas 15 cases were of partial spontaneous regression. There were five cases of lung metastasis and three cases of bone metastasis. In addition, six tumors of spontaneously regressed HCC might have lost their vascularity during the clinical course.

Thirty-two cases of spontaneous regression of HCC published in the literature in English from 2002 to 2012 are summarized in Table 2. Thirteen of these reported complete regression. There 

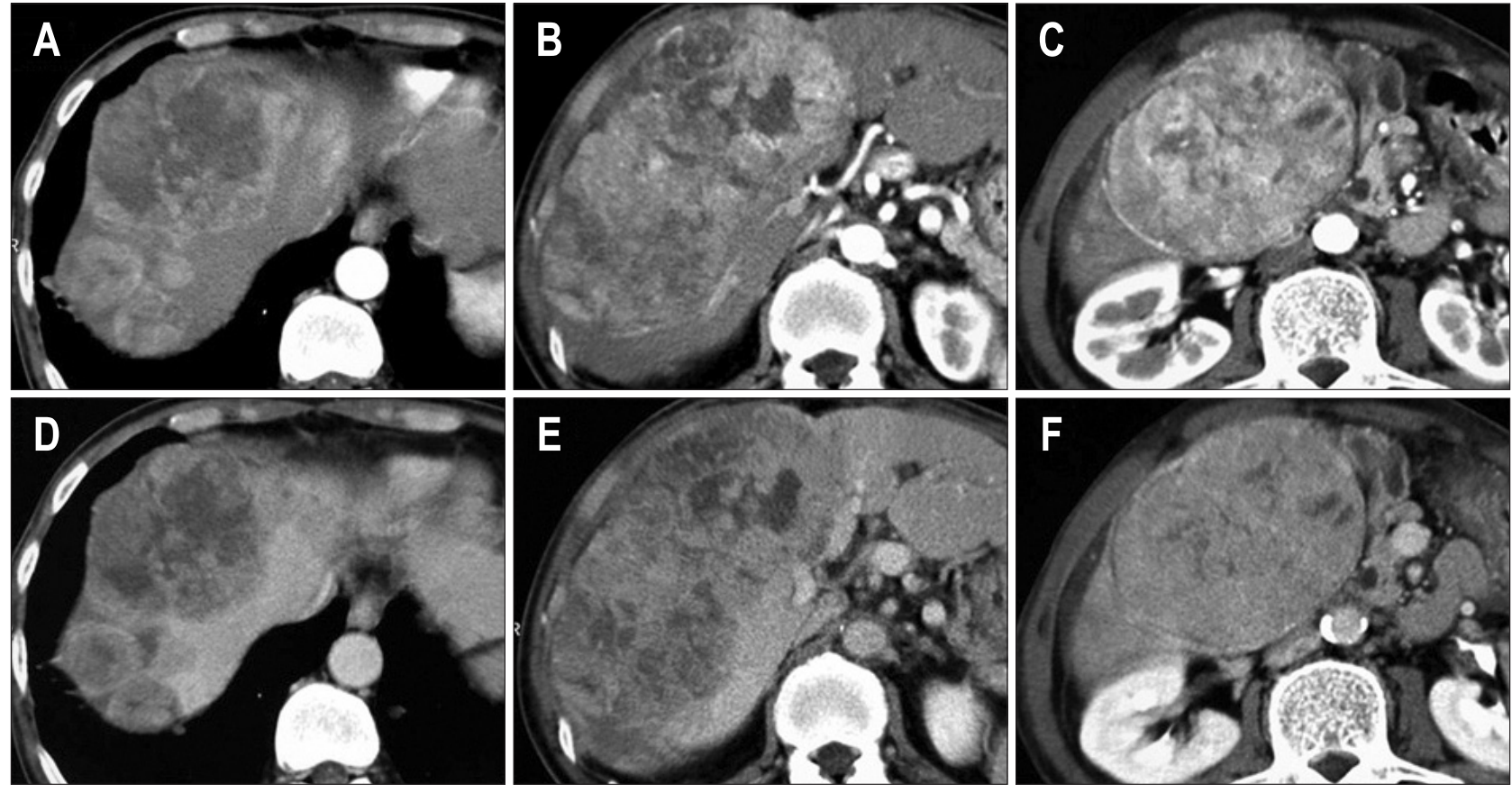

Fig. 1. Contrast-enhanced computed tomography showed a large heterogeneous dense mass with enhancement involving the right hepatic lobe The tumor was enhanced in the arterial phase (A-C) and washed out in the delayed phase (D-F), with central necrosis.
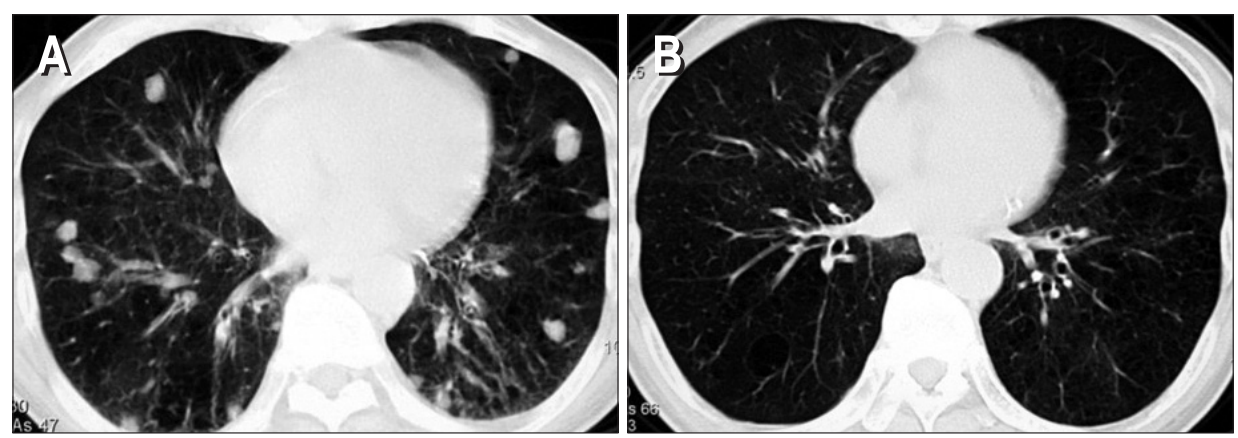

Fig. 2. Computed tomography of the chest showed multiple nodules in the bilateral lungs, ranging up to 15 $\mathrm{mm}$ in diameter (A). After 9 months, the multiple nodules in the bilateral lungs had disappeared (B).
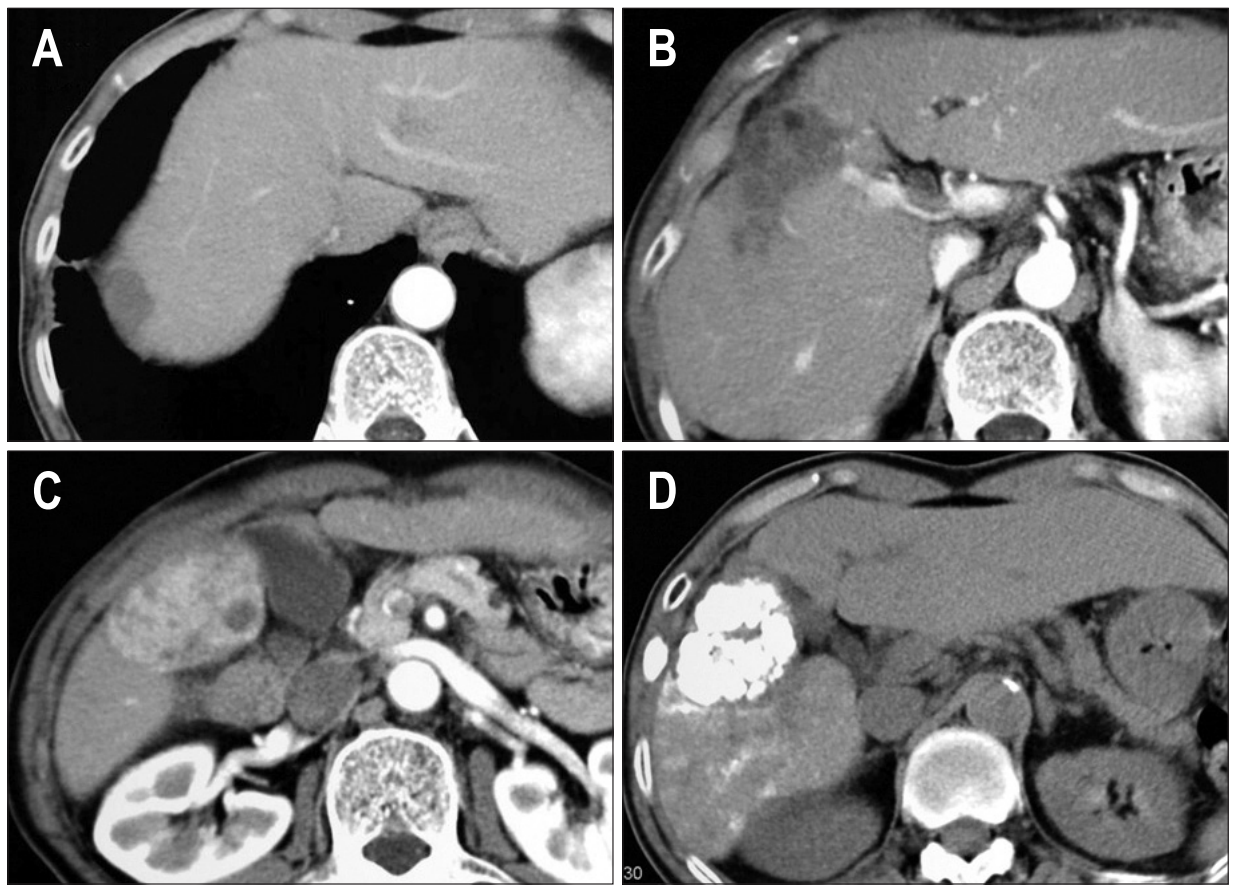

Fig. 3. After 13 months, a tumor 5 $\mathrm{cm}$ in size was detected in segmen $5 / 6$ of the liver in the arterial phase (A-C). Lipiodol accumulated after the first transcatheter arterial chemoembolization (D). 

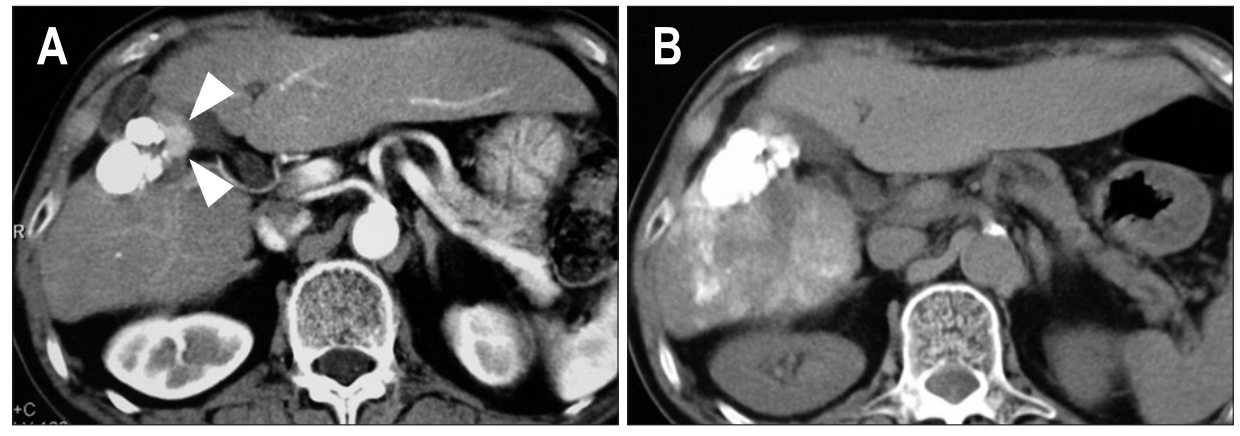

Fig. 4. At 13 months after the first treatment, local relapse (arrowheads) was observed on follow-up computed tomography (A), and increased lipiodol accumulation was observed after the second transcatheter arterial chemoembolization (B).

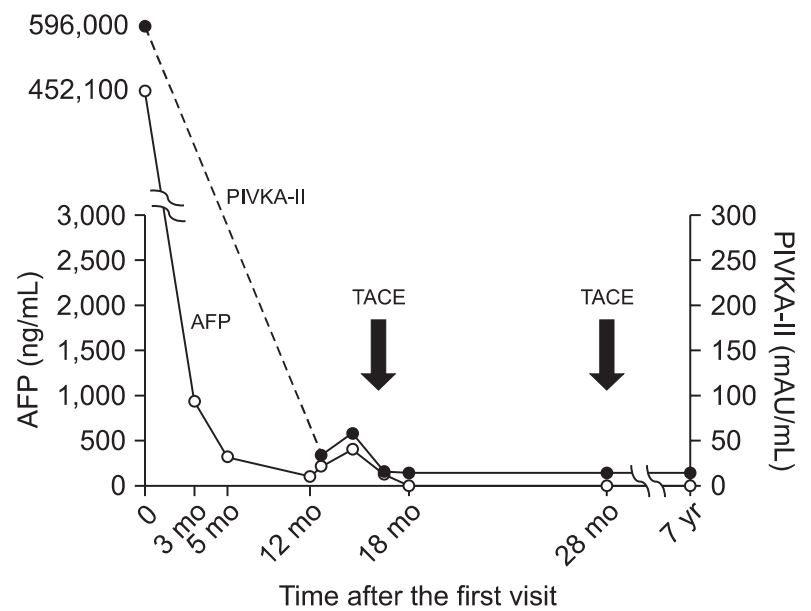

Fig. 5. Clinical course of the patient.

AFP, $\alpha$-fetoprotein; PIVKA-II, protein induced by vitamin $\mathrm{K}$ absence/ antagonist-II; TACE, transcatheter arterial chemoembolization.

were six cases of lung metastasis and one case of bone metastasis. The existence of portal vein thrombus or invasion was reported in 12 cases.

Kumar et al. ${ }^{6}$ analyzed 70 cases of chest metastatic tumors that regressed spontaneously according to reports from 1951 to December 2008. Renal cell carcinoma was the most common, accounting for 43 of 70 cases (60\%) and 34 of these cases (79\%) were reported to regress within a year of nephrectomy or other resection of the primary tumor. Other tumors such as HCC, endometrial stromal sarcoma, pleomorphic liposarcoma, esophageal cancer, and leiomyosarcoma were reported to regress spontaneously both in the primary tumor and in the thoracic metastases. Regression of metastatic lesion after removal of original tumor is due to another mechanism that is relief from immune suppression by the original tumor. Tumors such as HCC with high metabolic rates are susceptible to spontaneous regression in conjunction with a sudden fall in hepatic blood flow including rapid growth, arterioportal shunting, formation of a thick capsule, and portal vein thrombosis. ${ }^{7}$

Taking all of the evidence into consideration, the sequence of events in the present case can be speculated to be as follows: ischemia due to rapid growth of the neoplasia and immunologic mechanisms involving regression of the HCC with multiple lung metastases.

We have reported a case of a patient who showed partial spontaneous regression of a large HCC with multiple lung metastases. Spontaneous regression of HCC is very rare, and its mechanism remains unclear. Understanding the underlying mechanism of this rare phenomenon should offer hope for finding new therapies even in advanced metastatic situations.

\section{CONFLICTS OF INTEREST}

No potential conflict of interest relevant to this article was reported.

\section{REFERENCES}

1. Munoz N, Bosch X. Epidemiology of hepatocellular carcinoma. In: Okuda K, Ishak KG, eds. Neoplasms of the liver. Berlin: SpringerVerlag, 1987:3-19.

2. Everson TC, Cole WH. Spontaneous regression of cancer. Philadelphia: Saunders, 1966:6-7.

3. Cole WH. Efforts to explain spontaneous regression of cancer. J Surg Oncol 1981;17:201-209.

4. Chang WY. Complete spontaneous regression of cancer: four case reports, review of literature, and discussion of possible mechanisms involved. Hawaii Med J 2000;59:379-387.

5. Ohtani H, Yamazaki 0, Matsuyama M, et al. Spontaneous regression of hepatocellular carcinoma: report of a case. Surg Today 2005;35:1081-1086.

6. Kumar T, Patel N, Talwar A. Spontaneous regression of thoracic malignancies. Respir Med 2010;104:1543-1550.

7. Herrera A, Erdozain JC, Molina E, Conde P, Palomo V. Spontaneous regression of hepatocellular carcinoma. Am J Gastroenterol 1996;91:1288-1289.

8. Morimoto Y, Tanaka Y, Itoh T, Yamamoto S, Mizuno H, Fushimi H. Spontaneous necrosis of hepatocellular carcinoma: a case report. Dig Surg 2002;19:413-418.

9. Li AJ, Wu MC, Cong WM, Shen F, Yi B. Spontaneous complete necrosis of hepatocellular carcinoma: a case report. Hepatobiliary Pancreat Dis Int 2003;2:152-154.

10. Cheng HM, Tsai MC. Regression of hepatocellular carcinoma spontaneous or herbal medicine related? Am J Chin Med 2004;32:579- 


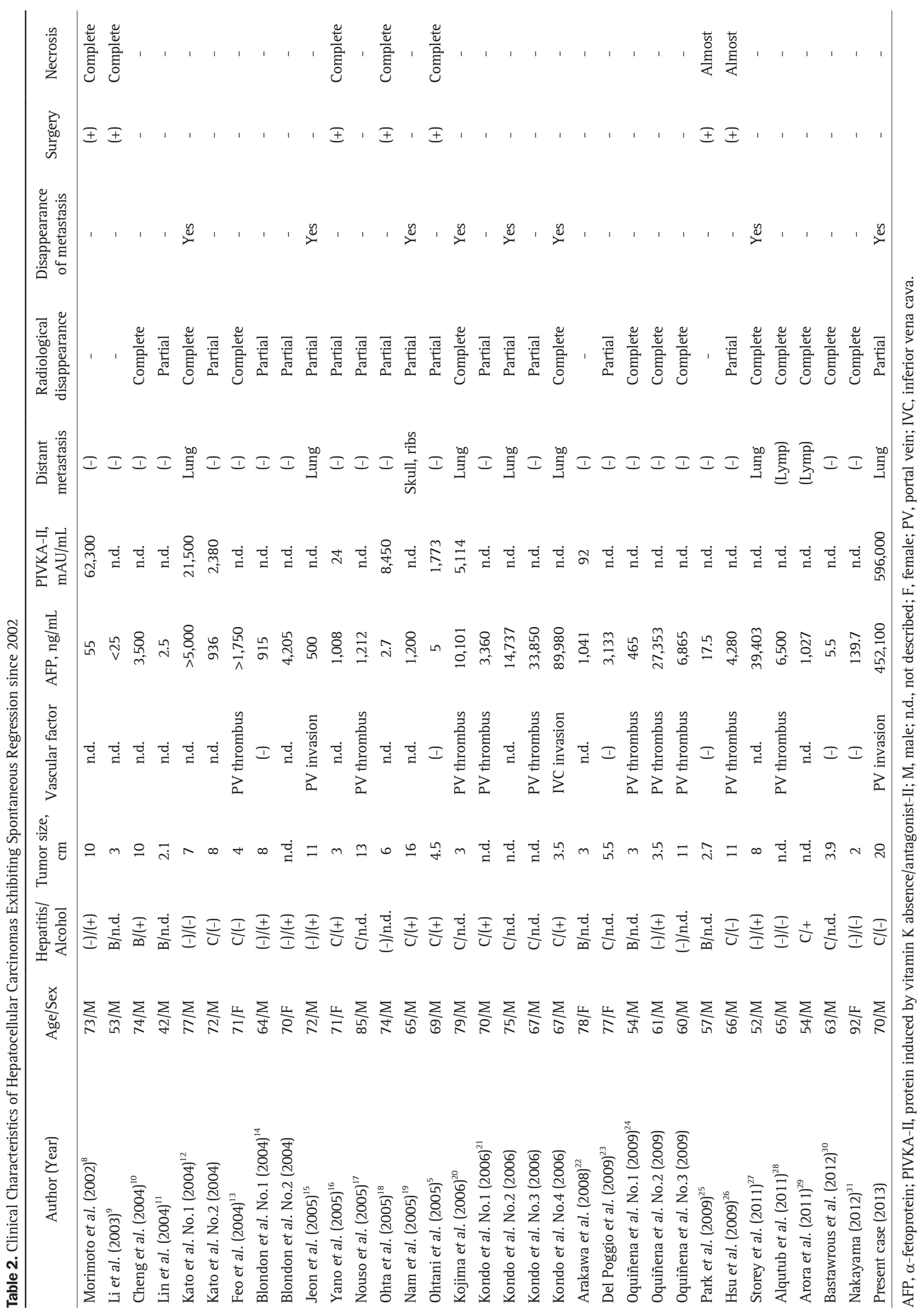


585.

11. Lin TJ, Liao LY, Lin CL, et al. Spontaneous regression of hepatocellular carcinoma: a case report and literature review. Hepatogastroenterology 2004;51:579-582.

12. Kato H, Nakamura M, Muramatsu M, Orito E, Ueda R, Mizokami M. Spontaneous regression of hepatocellular carcinoma: two case reports and a literature review. Hepatol Res 2004;29:180-190.

13. Feo CF, Marrosu A, Scanu AM, et al. Spontaneous regression of hepatocellular carcinoma: report of a case. Eur J Gastroenterol Hepatol 2004;16:933-936.

14. Blondon H, Fritsch L, Cherqui D. Two cases of spontaneous regression of multicentric hepatocellular carcinoma after intraperitoneal rupture: possible role of immune mechanisms. Eur J Gastroenterol Hepatol 2004;16:1355-1359.

15. Jeon SW, Lee MK, Lee YD, et al. Clear cell hepatocellular carcinoma with spontaneous regression of primary and metastatic lesions. Korean J Intern Med 2005;20:268-273.

16. Yano Y, Yamashita F, Kuwaki K, et al. Partial spontaneous regression of hepatocellular carcinoma: a case with high concentrations of serum lens culinaris agglutinin-reactive alpha fetoprotein. $\mathrm{Ku}-$ rume Med J 2005;52:97-103.

17. Nouso K, Uematsu S, Shiraga K, et al. Regression of hepatocellular carcinoma during vitamin $\mathrm{K}$ administration. World J Gastroenterol 2005;11:6722-6724.

18. Ohta H, Sakamoto Y, Ojima H, et al. Spontaneous regression of hepatocellular carcinoma with complete necrosis: case report. Abdom Imaging 2005;30:734-737.

19. Nam SW, Han JY, Kim JI, et al. Spontaneous regression of a large hepatocellular carcinoma with skull metastasis. J Gastroenterol Hepatol 2005;20:488-492.

20. Kojima H, Tanigawa N, Kariya S, et al. A case of spontaneous regression of hepatocellular carcinoma with multiple lung metastases. Radiat Med 2006;24:139-142.
21. Kondo S, Okusaka T, Ueno H, Ikeda M, Morizane C. Spontaneous regression of hepatocellular carcinoma. Int J Clin Oncol 2006;11:407-411.

22. Arakawa Y, Mori H, Ikegami T, et al. Hepatocellular carcinoma with spontaneous regression: report of the rare case. Hepatogastroenterology 2008;55:1770-1772.

23. Del Poggio P, Mattiello M, Gilardoni L, Jamoletti C, Colombo S, Zabbialini G. The mysterious case of spontaneous disappearance of hepatocellular carcinoma. Dig Liver Dis 2009;41:e21-e25.

24. Oquiñena S, Iñarrairaegui M, Vila JJ, Alegre F, Zozaya JM, Sangro B. Spontaneous regression of hepatocellular carcinoma: three case reports and a categorized review of the literature. Dig Dis Sci 2009;54:1147-1153.

25. Park HS, Jang KY, Kim YK, Cho BH, Moon WS. Hepatocellular carcinoma with massive lymphoid infiltration: a regressing phenomenon? Pathol Res Pract 2009;205:648-652.

26. Hsu CY, Sun PL, Chang HC, Perng DS, Chen YS. Spontaneous regression of advanced hepatocellular carcinoma: a case report. Cases J 2009;2:6251.

27. Storey RE, Huerta AL, Khan A, Laber DA. Spontaneous complete regression of hepatocellular carcinoma. Med Oncol 2011;28:948950.

28. Alqutub A, Peck D, Marotta P. Spontaneous regression of a large hepatocellular carcinoma: case report. Ger Med Sci 2011;9:Doc07.

29. Arora N, Madhusudhana S. Spontaneous regression of hepatocellular cancer: case report and review of literature. Gastrointest Cancer Res 2011;4:141-143.

30. Bastawrous S, Kogut MJ, Bhargava P. Spontaneous regression of hepatocellular carcinoma in a cirrhotic patient: possible vascular hypothesis. Singapore Med J 2012;53:e218-e221.

31. Nakayama S. Spontaneous regression of hepatocellular carcinoma Indian J Gastroenterol 2012;31:267-270. 